\title{
REFLEXÕES SOBRE A CRISE DEMOCRÁTICA
}

\section{Rosmar Rissi *}

\section{RESUMO}

Fator gerador de crise estatal, a globalização, a qual permitiu que os mercados livres gerassem ao longo do tempo, desigualdades em determinados setores da economia. A finalidade é investigar a formação do Estado e as denominações de democracia e o efeito da crise nos direitos fundamentais. Apesar das garantias serem plausíveis, para a perfeita efetivação e continuidade dos direitos fundamentais, faltam esforços, investimentos e atitudes políticas, para a sua viabilidade. Todavia, a democracia deliberativa é o caminho mais seguro na positivação e garantia dos direitos fundamentais e na superação de períodos de crise democrática.

Palavras-chave: Democracia; Cidadania; Crise; Transformação; Direitos fundamentais.

\section{REFLECTIONS ON THE DEMOCRATIC CRISIS}

\begin{abstract}
Factor that generated the state crisis, globalization, which allowed free markets to generate, over time, inequalities in certain sectors of the economy. The purpose is to investigate the formation of the State and the denominations of democracy and the effect of the crisis on fundamental rights. Although the guarantees are plausible, for the perfect realization and continuity of fundamental rights, efforts, investments and political attitudes are lacking, for their viability. Deliberative democracy, however, is the safest way to positivize and guarantee fundamental rights and to overcome periods of democratic crisis.
\end{abstract}

Keywords: Democracy; Citizenship; Crisis; Transformation; Fundamental rights.

\section{INTRODUÇÃO}

A democracia exerce papel decisivo no desenvolvimento da sociedade, assumindo especial relevância na preservação da plenitude e na concretização dos direitos fundamentais em todas as suas dimensões. Cumpre que haja a valorização do ser humano como pessoa, e não como objeto de utilização, a fim de obter valores financeiros, através da exploração do potencial humano. O Estado não é a única instituição em condições de garantir os direitos fundamentais sociais, mas é a única para validar a realidade de novos direitos sociais.

* Mestre em Direito pela UNISINOS, CAPES 6. Especialização em Gestão Estratégica de Pessoa e Especialização em Direito do Trabalho e Processo do Trabalho pela PUCRS. Especialização em Formação para a Vida Religiosa, pela ESTEF. Graduado em Direito, pela PUCRS. Autor de livros, entre eles (Teoria do Mínimo existencial: Direitos Fundamentais Sociais e Democracia), e com diversos artigos publicados. Advogado. Contato: rosmarrissi@gmail.com 
Entretanto, a Constituição Federal (CF), de 1988 foi a que consolidou os Direitos fundamentais e se firmou como a Constituição cidadã em razão da sua forma e matéria. Desta forma, a CF abrange diversas espécies de direitos, sendo eles coletivos, individuais, políticos, etc. (CANOTILHO, 2013).

A efetivação dos direitos fundamentais está conectada com a noção do Estado Democrático de Direito construído a partir do preenchimento de lacunas ao longo da história, em que apontam promessas como a igualdade, justiça social e a garantia dos direitos fundamentais e sociais. (STRECK, 2013, p.150).

O problema suscitado no presente artigo é a efetivação dos direitos fundamentais num contexto político fragilizado, onde o estado democrático em crise, perde o foco de sua real finalidade, e não apresenta as condições estruturais necessárias para a garantir de direitos mínimos a seus cidadãos.

Como hipótese, é possível considerar que mesmo em situações de adversidade, a estrutura estatal é consolidada o suficiente para garantir os direitos fundamentais. A estrutura estatal, paulatinamente precarize o acesso ao mínimo de direitos para a existência humana, deixando seus cidadãos em péssima situação mediante a crise político democrática. Que mesmo o Estado tendo seus dirigentes envolvidos em atos que fortalecem a crise, a cooperação democrática e os mecanismos de informação e pesquisas, com as políticas públicas focadas, é possível atravessar períodos de crise garantindo os direitos fundamentais.

Tem-se por finalidade, investigar a formação do estado e as denominações de democracia frente a continuidade dos direitos fundamentais. Compreender o efeito de uma crise democrática na efetividade dos direitos fundamentais. Demonstrar que o Estado possui condições de garantir a efetividade dos direitos fundamentais, mesmo em período de crise, através de meios como o judiciário e uma gestão eficiente dos recursos públicos.

O presente artigo tem como perspectiva de pesquisa o método fenomenológicohermenêutico. Considerando que o método de abordagem objetiva aproxima o sujeito (pesquisador) do objeto a ser pesquisado, onde se analisa o conceito do Estado Democrático de Direito e os direitos fundamentais, em seguida é feito um breve estudo da formação política brasileira e, por fim, analisar-se-á a relação com a atual crise que envolve a democracia e, dentro de uma sociedade que se declara democrática pós-constituição de 1988.

Por fim, será traçada a emergência de uma mudança de paradigmas, por meio de ideais éticos de proteção, pois, assim como a geração atual vive em uma época de 
consequências das ações tomadas pela anterior, as gerações futuras, sujeitos de direitos, dependem das escolhas feitas hoje, considerando, assim, o próprio conceito de humanidade.

O futuro dos direitos fundamentais está atrelado a condução democrática e eficiência administrativa estatal. A crise que envolve determinados países democráticos, é uma ameaça real a todo o sistema de garantias de direitos, colocando em dúvida da eficácia do próprio Estado Democracia de Direito, como o melhor sistema de governo.

\section{O ESTADO DEMOCRÁTICO DE DIREITO E OS DIREITOS FUNDAMENTAIS}

O surgimento do Estado, segundo Jacques Chevallier, como condição para o desenvolvimento econômico e a paz social, tem sua construção resultante da conjugação de cinco elementos essenciais, a saber: a existência de um grupo humano, a nação; a construção de uma figura abstrata, o Estado; a percepção do Estado como princípio de ordem e de coesão social; o estabelecimento de um monopólio da coerção; a existência de um aparelho estruturado e coerente de dominação, as burocracias funcionais. É a partir destes cinco elementos conjugados na construção do Estado e da forma estatal que reside à especificidade e a novidade. (CHEVALLIER, 2009, p. 24-25).

Na definição e compreensão de Canotilho, no Brasil, o termo Estado de Direito foi substituído por Estado Democrático de Direito, incorporado na Constituição Federal de 1988 como o garantidor do efetivo exercício dos direitos civis, sociais, liberdades, entre outros direitos. Está explícito no Preâmbulo e definido pelo Artigo $1^{\circ}$, ligado ao princípio da legalidade e concretizar o princípio da igualdade, é o núcleo-base em que se acopla a democracia e os direitos humanos fundamentais conquistados. (CANOTILHO, 2013, p.116).

O objetivo do Estado Democrático de Direito, é permitir que o Estado garanta as liberdades civis e os direitos e garantias fundamentais, além dos direitos humanos através da proteção jurídica constituída. O preâmbulo da Constituição de 1988, estabelece a figura do Estado Democrático de Direito que assegura os direitos e garantias fundamentais, também no art. 1, §́nico tem-se referência a questão. Além de buscar a garantia de direitos, o Estado democrático visa a separação de poderes, que em nossa Constituição Federal está inserido no art. $2^{\circ}$ - "São Poderes da União, independentes e harmônicos entre si, o Legislativo, o Executivo e o Judiciário". O poder é um só, mas pode ser exercido de forma tripartite, é o aperfeiçoamento da teoria de Montesquieu. 
Para Moraes o Estado Democrático de Direito seria “caracterizador do Estado Constitucional, significa que o Estado se rege por normas democráticas, com eleições livres, periódicas e pelo povo, bem como o respeito das autoridades públicas aos direitos e garantias fundamentais" (MORAES, 2010, p. 06). Desta forma, o autor continua afirmando que o princípio democrático "exprime fundamentalmente a exigência da integral participação de todos e de cada uma das pessoas na vida política do país, a fim de garantir o respeito à soberania popular". (MORAES, 2010, p. 06).

Entretanto, para Dantas, o Estado Democrático de Direito seria a "conjugação do Estado de Direito com o regime democrático. Trata-se, portanto, do Estado submetido ao império da lei, ou seja, a um conjunto de normas que criam seus órgãos e estabelecem suas competências, que presumem a separação dos poderes, e que também fixam direitos e garantias fundamentais para a proteção do indivíduo contra eventuais arbitrariedades estatais, e no qual também se garante o respeito à denominada soberania popular, permitindo que o povo (o titular do poder) participe da decisões políticas do Estado, seja por meio de representantes eleitos, seja por meio de mecanismos de democracia direta." (DANTAS, 2014, p. 65-66).

Todavia, uma preocupação acerca do Direito no sentido em que é acolhido como transformador social, para que seja possível é preciso que o direito esteja atento as questões históricas e culturais de um povo, a função social deve ser contemplada dentro de um Estado Democrático de Direito. (STRECK, 2013, p.34).

$\mathrm{Na}$ seara dos direitos fundamentais e da evolução das dimensões e na busca de reconhecimento e afirmação, nota-se que são fruto de reivindicações, geradas por situações de injustiça e agressão a bens fundamentais e essenciais à vida humana. Norberto Bobbio (1992, p. 15-16), na obra A Era dos Direitos, afirma que “o processo de reconhecimento e afirmação dos direitos fundamentais revela que estes constituem categoria materialmente aberta e mutável”. Gregório Peces-Barba Martínez (1995, p. 113) assegura que até a Modernidade não se falava no termo direito fundamental. Nesse período, afirma o autor, "existia uma ideia de dignidade, de liberdade, de igualdade, ligada a autores clássicos como Platão, Aristóteles e Santo Tomás de Aquino".

Nos primórdios das Constituições escritas, os direitos fundamentais tiveram o seu reconhecimento e tentativas de classificação, através de diversos termos. Será adotada a 
expressão dimensão dos direitos fundamentais, tendo presente que a discordância reside essencialmente na esfera terminológica, pois, em princípio há consenso referente ao conteúdo.

A primeira dimensão, abrange os direitos de cunho negativo, presente direitos de defesa, demarcaram uma zona de não intervenção do Estado e uma esfera de autonomia individual em face de seu poder. (SARLET, 2012, p. 46). São direitos de cunho negativo, pois não obrigam o ente público a uma ação, mas sim à abstenção no poder de agir. Nessa exigência de conduta omissiva, além das intituladas garantias fundamentais, assim considerados não só os direitos-garantia, mas também as garantias institucionais revestidas de fundamentalidade. (SARLET, 2012, p. 47).

Na compressão de Ingo Sarlet, a segunda dimensão dos direitos fundamentais não é restrita aos direitos de cunho positivo, mas também às denominadas "liberdades sociais", que a exemplo da liberdade de sindicalização, do direito de greve, são voltadas a garantir os direitos fundamentais trabalhistas, citando como exemplo o direito a férias, ao repouso semanal remunerado, a um salário mínimo, à limitação da jornada de trabalho, ao intervalo intrajornadas e outros. Esta dimensão é mais abrangente do que os direitos de cunho prestacional, pois marca uma nova fase na evolução dos direitos fundamentais. (SARLET, 2012, p. 48).

A terceira dimensão dos Direitos fundamentais, engloba os Direitos de fraternidade ou de solidariedade. Esses direitos não possuem um titular especifico, ou seja, não pertencem a um único indivíduo, pois são destinados à proteção de grupos humanos, família, povo, nação, e sua titularidade é coletiva ou difusa. No consenso dos direitos da terceira dimensão cumpre citar os direitos à paz, à autodeterminação dos povos, ao meio ambiente, ao desenvolvimento e à qualidade de vida, e ainda o direito à conservação e utilização do patrimônio histórico e cultural e o direito de comunicação. (SARLET, 2012, p. 48).

O ponto importante dos direitos da terceira dimensão é a sua titularidade, a qual é sempre coletiva, e por vezes indefinida e indeterminável, pois não é possível determinar a quem pertence. Pois o direito do meio ambiente, da qualidade de vida, "a qual, em que pese ficar preservada sua dimensão individual, reclama por novas técnicas de garantia e proteção." (SARLET, 2012, p. 49).

Incluídas nesta dimensão as garantias contra a manipulação genética, o direito de morrer com dignidade, o direito à mudança de sexo, etc. Direitos esses que poderiam estar em outras dimensões, entretanto são deduzidos do princípio da dignidade da pessoa humana, da 
ideia de liberdade-autonomia e da proteção da vida e outros bens fundamentais. (SARLET, 2012, p. 50).

Referente a quarta e quinta dimensão dos Direitos fundamentais, a teoria não é passível quanto à problemática dessas dimensões, bem como a sua consagração na esfera do direito internacional e das ordens constitucionais internas.

Em síntese, sobre as diversas dimensões é possível afirmar que a proteção da vida, da liberdade, da igualdade e da dignidade da pessoa humana, ou seja, a garantia de todos os direitos fundamentais individuais ou coletivos é a finalidade do direito positivado constitucionalmente.

\section{1 - Os modelos de democracia na formação política}

Compreendida a relevância dos direitos fundamentais, e a sua necessidade de efetivação nas diversas dimensões, há que se adentrar em qual das teorias democráticas a sua efetivação ocorre, a fim de garantir a existência de um mínimo digno a quem é titular deste direito ou venha ser, bem como, compreender o impacto exercido sobre estes direitos, pela crise democrática.

Nesse quadro teórico serão abordadas algumas concepções de democracia, não que elas sejam uma continuidade ou uma evolução, mas sim uma maneira didática de exemplificar os conceitos teorizados pelos diversos doutrinadores.

Neste introito, é premente enfatizar que o termo Democracia enseja uma compreensão clara e original. Partindo de sua origem, do grego, demokratía resulta da união de demos (povo) e krátos (poder), bem como em sua continuidade, segundo o léxico, significa:

1. Governo do povo; soberania popular; democratismo [cf. vulgocracia.] 2. Doutrina ou regime político baseado nos princípios da soberania popular e da distribuição equitativa do poder, ou seja, regime de governo que se caracteriza, em essência, pela liberdade do ato eleitoral, pela divisão dos poderes e pelo controle da autoridade, i.e., dos poderes de decisão e de execução; democratismo. [cf. (nesta acepç.) ditadura (1).] 3. País cujo regime é democrático. 4. As classes populares; povo proletariado. [...]. (FERREIRA, 1995, p. 534). 
Para Ferrajoli (2008, p. 77), a democracia compreende o método para a tomada de decisões que envolvem a coletividade, ou seja, as regras que os representantes do povo devem assumir nas decisões, e assim enfatiza o autor exemplifica:

Segundo a concepção certamente dominante, a democracia consiste unicamente em um método de formação das decisões coletivas: precisamente no conjunto das regras que atribuem ao povo, e, portanto, à maioria de seus membros, o poder - direto ou através de representantes de assumir decisões. Esta não é a apenas a concepção etimológica de 'democracia', mas também a concepção unanimemente compartilhada desde Kelsen a Bobbio, de Schumpeter a Dahl da teoria e da filosofia política. (FERRAJOLI, 2008, p. 77). ${ }^{2}$

No resgate histórico, Platão na obra A República, cita cinco formas de governo, sendo elas "aristocracia, timocracia, oligarquia, democracia e tirania, só uma delas, a aristocracia, é boa." Refere-se à democracia como a que "nasce quando os pobres, após haverem conquistado a vitória, matam alguns adversários, mandam outros para o exílio e dividem com os remanescentes, em condições paritárias, o Governo e os cargos públicos, sendo estes determinados, na maioria das vezes, pelo sorteio”. (BOBBIO, 1998, p. 320).

A compreensão de democracia como poder do povo, emana do pensamento de se obter o consenso para o bem comum. Bobbio enfatiza que a democracia deve ser compreendida como "contraposta a todas as formas de governo autocrático caracterizada por um conjunto de regras (primárias ou fundamentais) que estabelecem quem está autorizado a tomar as decisões coletivas e com quais procedimentos". Destaca-se que todo agrupamento de pessoas "está obrigado a tomar decisões vinculatórias" para a sobrevivência de todos os integrantes que a ele pertençam. Entretanto, a participação da totalidade na tomada de decisão é praticamente inviável. Mesmo com o emprego da mais sofisticada tecnologia da informação atual, não seria possível atingir a todos os cidadãos. Com isso, "até mesmo as decisões de grupo são tomadas por indivíduos (o grupo como tal não decide).” (BOBBIO, 2011, p. 31).

$\mathrm{Na}$ doutrina democrática originária, não haveria intermediários entre o povo e seus representantes, bem como Rousseau desprezava as sociedades particulares, influência essa

\footnotetext{
${ }^{2}$ Ferrajoli enfatiza essa concepção no primeiro capítulo do livro Poderes selvagens, intitulado, el paradigma de la democracia constitucional.
} 
que resultou na Lei francesa denominada Le Chapelier ${ }^{3}$ de 1791, que foi revogada somente em 1887, sendo válida por um longo período. (BOBBIO, 2011, p. 35).

Perante disto, há dois modelos de democracia, que de per si, apresentam suas significativas diferenças. A democracia formal, em sua própria formulação denota a necessidade de procedimentos que visem a sua legalidade, e a democracia substancial que visa à garantia de todos os indivíduos pertencentes ao Estado. Reafirmando esta compreensão, Cadermatori enfatiza:

Enquanto a democracia formal refere-se ao Estado político representativo, que tem no princípio da maioria a fonte da legalidade, a democracia substancial ou social nada mais é do que o Estado de Direito dotado de garantias efetivas, tanto liberais quanto sociais.

São modelos independentes entre si, como são independentes os sistemas de garantias constitucionais inerentes: de um lado, as regras que asseguram a mera legalidade, ou seja, a vontade da maioria; de outro, as que garantem a estrita legalidade, a matéria a ser decidida. (CADERMATORI, 2011, p. 164).

Nessa linguagem política contemporânea, bem como na noção comportamental de Democracia, surge outro significado de democracia ${ }^{4}$, o qual compreende formas de regime político.

$\mathrm{Na}$ democracia formal pode ocorrer o favorecimento "de uma minoria restrita de detentores do poder econômico e, portanto não ser um poder para o povo, embora seja um Governo do povo", sendo também um caminho de perda da liberdade, tendo em vista um interesse exclusivo de determinado grupo. (BOBBIO, 1998, p. 328).

Na compreensão de Ferrajoli (2008, p. 77), a democracia formal, enfatiza o procedimentalismo oriundo da forma em si mesmo diante do sistema, tendo por objetivo que seja efetivamente garantida a vontade do povo, assim o autor define a democracia formal:

\footnotetext{
${ }^{3}$ A Lei Chapelier proibia os sindicatos, as greves e as manifestações dos trabalhadores. Era a represão da burguesia sobre a classe operaria.

${ }^{4}$ Tendo como paradigma a democracia dos países socialistas ou dos países do Terceiro Mundo, especialmente, dos países africanos, onde não vigoram ou não são respeitadas mesmo quando vigoram algumas ou todas as regras que fazem que sejam democráticos, já depois de longa tradição, os regimes liberais-democráticos e os regimes sociais-democráticos. (BOBBIO 1998, p. 328).

5 Salienta o autor também que "uma ditadura política pode favorecer em períodos de transformação revolucionária, quando não existem condições para o exercício de uma Democracia formal, a classe mais numerosa dos cidadãos, e ser, portanto, um Governo para o povo, embora não seja um Governo do povo". (BOBBIO, 1998, p. 328).
} 
Podemos chamar formal ou procedimental essa definição de democracia. $\mathrm{Na}$ verdade, ela identifica a democracia unicamente com base nas formas e procedimentos idôneos para garantir a vontade do povo: em outras palavras, sobre a base de 'quem' (o Povo ou seus representantes) e do 'como" (a regra da maioria), das decisões independentementes dos seus conteúdos, quaisquer que eles sejam. Inclusive um sistema no qual as decisões por maioria na supressão de uma minoria, seria, à luz deste critério, 'democrático'. (FERRAJOLI, 2008, p. 77).

Nesta seara da busca de uma democracia satisfatória, os modelos da democracia representativa e direta serão objeto de aclaração. Entretanto, Bobbio (2011), critica a democracia representativa, em prol da democracia direta, a qual não é perfeita, mas melhor, mesmo com ressalvas, como a de que nem todos precisam decidir sobre tudo. A partir desse contexto, da democracia representativa a qual deve ser compreendida com o seguinte enfoque:

A exigência, tão frequente nos últimos anos, de maior democracia exprimese como exigência de que a democracia representativa seja ladeada ou mesmo substituída pela democracia direta. Tal exigência não é nova: já a havia feito, como se sabe, o pai da democracia moderna, Jean-Jacques Rousseau, quando afirmou que 'a soberania não pode ser representada' e, portanto, 'o povo inglês acredita ser livre mas se engana redondamente; só o é durante a eleição dos membros do parlamento; uma vez eleitos estes, ele volta a ser escravo, não é mais nada' Rousseau entretanto também estava convencido de que 'uma verdadeira democracia jamais existiu nem existirá', pois requer muitas condições difíceis de serem reunidas. Em primeiro lugar um estado muito pequeno, 'no qual ao povo seja fácil reunir-se e cada cidadão possa facilmente conhecer todos os demais'; em segundo lugar, 'uma grande simplicidade de costumes que impeça a multiplicação dos problemas e as discussões espinhosas'; além do mais, 'uma grande igualdade de condições e fortunas'; por fim, ' pouco ou nada de luxo'. (BOBBIO, 2011, p. 53).

Todavia, Rousseau, ao afirmar que a soberania não pode ser representada, atribui ao indivíduo significativa importância social, bem como na impossibilidade da perfeição democrática.

Com isso emerge a necessidade de uma ampliação da democracia representativa, bem como também da democracia direita. Contudo, seria está a solução? Bobbio (2011, p. 54) delineia a questão para obter uma resposta. Aborda que a compreensão literal de democracia direta é a "participação de todos os cidadãos em todas as decisões a eles pertinentes", evidente que mesmo na tecnocracia é insensata a sua concretização. Diante da complexidade da sociedade moderna, e o desejo de todos decidirem sobre tudo, é materialmente impossível. 
$\mathrm{Na}$ atualidade e humanamente, não é desejável que a população esteja decidindo sobre tudo. Bobbio refere que "Marx havia indicado o homem total como meta do desenvolvimento civil da humanidade”. Este homem total somente seria possível tendo sua dedicação exclusiva nos seus deveres. "Mas o indivíduo rousseauniano conclamado a participar da manhã à noite para exercer os seus deveres de cidadão não seria o homem total, mas o cidadão total." E neste intuito pode ser interpretada como democracia totalitária em polêmica com a democracia liberal. (BOBBIO, 2011, p. 54).

Entretanto, Dworkin (2002) chega à conclusão de que a democracia representativa é adequada, mas imperfeita para a sociedade atual, devido à complexidade e à diversidade existentes, bem como os interesses individuais que distorcem a real forma da democracia representativa, em seu resultado desejado, ou seja, a preferência real dos eleitores.

Contudo, por mais importante que seja esta conclusão no nível da filosofia política, ela é em si mesma de importância prática limitada, porque é impossível conceber procedimentos políticos que discriminem com precisão entre preferências pessoais e externas. A democracia representativa é amplamente concebida como a estrutura institucional mais adequada, em uma sociedade complexa e diversificada, para a identificação e a consecução de políticas utilitaristas. Nesse ponto ela funciona imperfeitamente, pela conhecida razão de que a regra de decisão pela maioria não consegue levar suficientemente em conta a intensidade, por oposição ao número, das preferências particulares, e porque as técnicas de persuasão política, apoiadas pelo dinheiro, podem corromper a precisão com a qual os votos representam as verdadeiras preferências dos eleitores. (DWORKIN, 2002, p. 425).

O desvirtuamento da democracia e a origem da crise, advém a partir de procedimentos não condizentes com a forma adequado de governo, e neste ponto, Dworkin demonstra que o lobby, artimanha proibida em diversos países democráticos, é fator de imperfeição para a democracia representativa, pois há poderes velados como o potencial econômico e o tráfico de influência por interesses particulares.

Compreender as formas de governo democrático denominadas democracia liberal e social, as quais diferem em sua conduta perante o povo, é relevante para a compreensão do efeito de governo na sociedade. O termo liberal compreendido como liberdade, e social como o bem comum.

Neste viés, quem visa aumentar cada vez mais a esfera das ações não impedidas é liberal, e quem persegue ações que tendem a aumentar o número das ações reguladas 
mediante o processo de autorregulamentação, é democrata: por conseguinte, estado liberal é aquele em que a ingerência do poder público está restrita ao mínimo possível; estado democrático, aquele em que mais numerosos são os órgãos de autogoverno. (BOBBIO, 1985, p. 197).

Ora, os mecanismos constitucionais do Estado de direito objetivam a defesa dos indivíduos contra os abusos do poder, o que, em suma, constitui a defesa da liberdade negativa, entendida como esfera de ação em que o indivíduo não está obrigado por quem detém o poder coativo a fazer aquilo que deseja ou não está impedido de fazer aquilo que deseja. Nesta acepção a liberdade opõe-se ao poder, sendo com ele incompatível: à medida que aumenta o poder, diminui a liberdade.

No pensamento liberal, teoria do controle do poder e teoria da limitação das tarefas do Estado procedem no mesmo passo: pode-se até mesmo dizer que a segunda é a conditio sine qua non da primeira, no sentido de que o controle dos abusos do poder é tanto mais fácil quanto mais restrito é o âmbito em que o Estado pode estender a própria intervenção, ou mais breve e simplesmente no sentido de que o Estado mínimo é mais controlável do que o Estado máximo. (BOBBIO, 2000, p. 20).

Por outro lado, é fato incontestável que a história do Estado liberal coincide com o fim dos Estados confessionais e dos privilégios feudais, na medida em que propõe o Estado neutro ou agnóstico e também a livre disposição dos bens e da liberdade de troca, assinalando assim o surgimento da sociedade mercantil burguesa.

Sob esse aspecto, a concepção liberal do Estado contrapõe-se às várias formas de paternalismo, segundo as quais o Estado deve tomar conta de seus súditos tal como o pai de seus filhos, posto que os súditos são considerados como perenemente menores de idade. Um dos fins a que se propõe Locke com os seus dois Ensaios sobre o Governo é o de demonstrar que o poder civil, nascido para garantir a liberdade e a propriedade dos indivíduos que se associam com o propósito de se autogovernar, é distinto do governo paterno e mais ainda do patronal. (BOBBIO, 2000, p. 22).

A diferença entre as teorias liberal e democrática reside em que a primeira tende a restringir o poder coletivo e a dilatar a esfera da autodeterminação individual, enquanto a segunda dilata a esfera da autodeterminação coletiva, restringindo a regulação heterônoma. (BOBBIO, 1985, p. 198). 
A teoria liberal considera o problema da liberdade em função do indivíduo isolado, enquanto a teoria democrática o faz em função do indivíduo enquanto membro de uma coletividade.

Nicola Matteucci (1983, p.702), por outro lado, ao mencionar os dois grandes desafios históricos que o liberalismo precisou enfrentar, afirma que o segundo envolve a relação do liberalismo com a democracia. No primeiro deles, o liberalismo afirma-se no confronto que levou à transformação da monarquia medieval em monarquia absoluta e burocrática, tendo como ponto de partida a reivindicação dos direitos naturais do indivíduo e a afirmação do princípio da separação dos poderes. Por esse princípio, ao mesmo tempo em que ficaria assegurada a independência do poder judiciário, transformado em mero aplicador do direito, deixava-se com o monarca a titularidade do poder executivo e com os representantes do povo a tarefa de definir, através da lei, a vontade comum da nação.

O segundo desafio histórico diz respeito à relação entre liberalismo e democracia. Ele obteve, por parte do primeiro, várias respostas: ampliação dos direitos eleitorais, marginalização da câmara hereditária, que se transformou, posteriormente, também em eletiva, divisão do poder político vertical, autonomias locais, federalismo e horizontalmente, de forma a que a antítese maioria-minoria substituísse a antítese rei-parlamento. (MATTEUCCI, 1983, p. 702).

Em uma passagem magistral, Bobbio (1983a, p. 64) mostra que as relações democracia/liberalismo, e democracia/socialismo não são tranquilas, já que a democracia é subversiva: E é subversiva, no sentido mais radical da palavra porque, "subverte a concepção tradicional de poder tão tradicional que chega a ser considerada natural, segundo a qual, o poder político ou econômico, paterno ou sacerdotal, desce do alto para baixo". Ela é mais subversiva que o socialismo, caso este último seja entendido, como quase sempre, apenas como a transferência da propriedade dos meios de produção das mãos privadas para as do Estado, como uma forma de poder que vem de cima para baixo.

Tão subversiva é a democracia que se fosse realmente e plenamente realizada, segundo a ideia-limite de Rousseau, seria ela, e não a hipotética sociedade sem classes, o fim do Estado, a sociedade sem Estado (porque o Estado, qualquer Estado que tenha existido até hoje, nunca pôde dispensar as relações de poder descendente). Apesar de Marx e de cem anos de socialismo prático e realizado, o problema fundamental do homem moderno, problema não resolvido (resolvível) é aquele que foi colocado, ainda que através de fórmula sugestiva, mas ambígua, por Rousseau: como pode o 
indivíduo, alienando a própria liberdade ao corpo político do qual faz parte, ser ... 'mais livre que antes'? (BOBBIO, 1983 a, p. 64).

A contribuição que o liberalismo se propõe a oferecer a um reformismo democrático envolve a ideia de que a conciliação entre a liberdade econômica e a justiça social não é um problema ético e sim, prático, de correspondência entre meios e fins. De acordo com Matteucci (1983, p. 703), “A melhor percepção do liberalismo ocidental contemporâneo é feita por pensadores interessados na política econômica, diferindo entre eles quanto ao medo ou não de que o Estado assistencial leve o liberalismo à bancarrota”.

$\mathrm{O}$ voto não deve ser o único instrumento de democracia do povo, visto que a Constituição traz outras formas de participação como a ação popular, a iniciativa de projetos de lei, o referendo e mesmo o plebiscito. Assim, a democracia sofre alterações na sociedade, segundo José Afonso da Silva (2003, p.141) a Democracia seria "processo de convivência social em que o poder emana do povo, há de ser exercido, direta ou indiretamente, pelo povo e em proveito do povo". E, continua o autor afirmando que "as primeiras manifestações da democracia participativa consistiram nos institutos de democracia semidireta, que combinam instituições de participação direita com instituições de participação indireta”. (SILVA, 2003. p. 139-140).

A forma de democracia participativa atual, limita a atuação do indivíduo, ser um cidadão não significa somente contribuir com o voto, mas usar dos meios disponíveis para atuar junto ao governo.

A democracia deliberativa leva em consideração um contexto de atuação livre e igualitária, que essa atuação tanto do poder público quanto do privado e todos que façam parte da sociedade participem em sua plena capacidade igualitária, em mesmas condições, de persuadir e influenciar.

Por fim, cabe aqui o intento de trazer à tona a ideia de que os meios disponíveis para utilizar do seu direito de atuar em uma sociedade democrática precisam ser a ele ensinados, levando em consideração uma cultura a ser implantada. Por mais modernos que se digam, com todos os meios de informação ao dispor, uma sociedade que conquistou direitos e garantias através de lutas e manifestações, não pode se tornar passiva, nem tampouco ativa de forma a ser influenciada por meios não dignos de atenção, que da mesma forma buscam a influência de massa de tal forma a satisfazer apenas os interesses de um lado. 
Entretanto, para onde vai a democracia? A difícil democracia que permeia a sociedadde, envolta por produnfas transformações na produção capitalista, no domínio das forças produtivas, e no domínio das relações de produção. Por um lado, os avanços tecnológicos nas linhas e nos processos de produção, a revolução nas tecnologias de informação e de comunicação e o embaratecimento dos transportes alteraram profundamente a natureza, a lógica, a organização e as hierarquias do trabalho industrial. A partir disso, ocorre a deterioração das condições de vida dos trabalhadores, o agravamento das desigualdades de poder e da injustiça social causadas pela nova fase do capitalismo global a que se convencionou chamar "globalização" ou "neoliberalismo". Fatores estes que a evidenciaram a ineficiência, o colapso, a crise de governos sob o regime democrático.

\section{3 - A CRISE DOS PODERES E A DEMOCRACIA}

A partir de meados do século passado, o mundo vem registrando um estado de profunda crise mundial, independente do sistema de governo, que é verdadeiramente complexo. É uma crise que engloba diversas dimensões, afetando todos os aspectos da vida do homem, a saúde e o modo de vida, a qualidade ambiental, as relações sociais, a economia, a tecnologia e a política, demonstrando que, pela primeira vez, a humanidade se defronta com a sua real ameaça de extinção.

\section{1 - O Estado e a crise na democracia}

A atual situação de crise na democracia representativa, demanda movimentos por reformas ao sistema político representativo. Uma vez que esse sistema é instável e não permite uma política programática, em virtude de a atual, funcionar como negócio na lógica do toma cá e dá lá, gerando políticos corruptos, como o caso da ascensão dos movimentos Occupy e das revoltas da indignação, do Mensalão e da operação Lava Jato, entre seus desdobramentos.

O surgimento de novos direitos ou a transformação não tende a ocorrer na democracia representativa, tendo em vista os interesses diversos de cada partido que representa o povo. A crítica ao modelo representativo, como referido, deve-se ao fato de que mesmo com a evolução tecnológica e a demanda por novos direitos, o sistema democrático representativo não acompanhou a evolução da representação. 
Entretanto, a atualidade pode ser comparada aos herdeiros da Era das Luzes ${ }^{6}$ que são apoplécticos: as leis se converteram em receitas, o Direito em método e o Estado Constitucional Moderno em meros espaços jurídicos incapazes de enfrentar os desafios transnacionais. A grande questão a ser respondida é se isso é suficiente para assegurar o futuro da Democracia. É preciso perguntar, hoje, como será a Democracia sem soberania nacional. O grande edifício da era moderna perdeu seus alicerces e flutua livre de todas as amarras, abandonado a si mesmo, feito papel carregado pelo vento, como escreve Ferrajoli (2004, p. 151).

No momento atual a Sociedade Mundial está carente de um upgrade civilizatório. As últimas gerações humanas são devedoras de um efetivo novo avanço do que se pode chamar de um mundo solidário e humanizado. A modernidade caracterizou um significativo avanço, apesar de um avanço baseado no individualismo. O mundo atual é complexo demais para seus obsoletos paradigmas teóricos.

E diante desta complexidade da democracia em crise, o surgimento de organismos supranacionais, como a OMC (Organização Mundial do Comércio), o GATT (Acordo sobre Tarifas Aduaneiras e Comércio), o bloco econômico da União Europeia, a ONU (Organização das Nações Unidas) e outras, como a UNASUL e MERCOSUL, tendo como fator de força a meramente a questão econômica. Creveld descreve como intervenção necessária ao equilíbrio global afirmando: "O funcionamento da economia mundial foi enquadrado pela intervenção das organizações, chamadas a intervir permanentemente para assegurar a manutenção de um equilíbrio global”. (CREVELD, 2004, p. 42).

Mesmo diante de toda essa crise Estatal descrita, o doutrinador Georg Sorensen afirma ser o Estado um ente pleno de poder, com domínio sobre as forças econômicas globais, bem como enfatiza os movimentos populares, como forças que impactam na organização do ente público, in verbis:

El mundo está cambiando y se ha abierto un nuevo debate acerca del destino del Estado. El Estado sigue siendo la forma dominante de la organización política universal, pero se lo desafía desde ámbitos muy distintos, incluidos

\footnotetext{
${ }^{6}$ Século das luzes: Termos usados para descrever as tendências do pensamento e da literatura na Europa e em toda a América durante o século XVIII, antecedendo a Revolução Francesa. Foram empregados pelos próprios escritores do período, convencidos de que emergiam de séculos de obscurantismo e ignorância para uma nova era, iluminada pela razão, a ciência e o respeito à humanidade. As novas descobertas da ciência, a teoria da gravitação universal de Isaac Newton e o espírito de relativismo cultural fomentado pela exploração do mundo ainda não conhecido foram também importantes para a eclosão do Iluminismo.
} 
las fuerzas mercantiles globales, las instituciones intemacionales y los movimientos populares. (SORENSEN 2010, p. 41).

Aspecto relevante também é a função institucional do Judiciário, como forma de garantir uma integridade e confiabilidade perante os cidadãos, busca cada vez mais inibir iniciativas que trazem prejuízos a sociedade. $\mathrm{O}$ autor refere-se à França e a Itália, entretanto, os meios de comunicação no Brasil também em muito divulgam ações de combate a corrupção. Os regimentos internos de cada poder político constituído preveem punição e moralização para o combate a esse crime. Destarte, Chevallier assim descreve a tentativa de superação da crise nos países europeus:

Dessa vez, magistrados vão se engajar, em nome da luta contra a corrupção, na repressão das práticas de corrupção política, não hesitando em questionar diretamente os eleitos. Vê-se proliferar a figura nova do juiz justiceiro, que assume a missão de sanear e moralizar a vida política.

$\mathrm{Na}$ Itália, como na França, a iniciativa virá dos magistrados inquisidores ou instrutores, que vão estender o terreno de suas investigações na direção dos políticos. Utilizando com habilidade os instrumentos do processo penal e jogando plenamente com os meios de comunicação para assegurar o apoio da opinião pública, os magistrados não hesitam mais em processar os responsáveis políticos, até ao mais alto nível. (CHEVALLIER, 2009, p. 210).

Fator gerador de crise estatal, a globalização, a qual permitiu que os mercados livres gerassem ao longo do tempo desigualdades em determinados setores da economia, sendo que os que mais sofrem são aqueles com menos aporte financeiro em suas políticas públicas. Uma das possíveis soluções é a regulação de toda essa economia, seja interna ou por organismos paraestatais. Na concepção de Marcelo Neves, o transconstitucionalismo apontaria a solução viável na medida em que haveria regras universais. Chevallier, invoca a atuação do Fórum Social Mundial o qual, propõem que um outro mundo é possível, desejando as transformações na função do Estado.

Defensores de uma globalização diferente: Fórum Social Mundial e europeu. De uma parte, a tomada de consciência dos excessos da globalização conduziu a antecipar a necessidade de uma regulação: essa regulação aparece indispensável, não somente para corrigir as desigualdades de todas as ordens que a globalização gera, mas ainda para garantir o bom funcionamento da economia mundial.

Por outro lado, uma verdadeira 'ética da globalização' se esboça através da consagração de novas exigências. 
A dimensão social, que havia passado ao segundo plano sob a pressão da concorrência e a dominação de valores liberais, tende a retornar com força. (CHEVALLIER, 2009, p. 40).

Conforme se pode perceber nem tudo o que faz parte da globalização é benéfico a toda sociedade e aos cidadãos. Chevallier, faz referência ao desenvolvimento de uma criminalidade transfronteiriça, através da indústria do sexo, da formação de redes mafiosas transnacionais, do comércio de drogas e a reciclagem dos fluxos de dinheiro sujo, algumas formas de terrorismo radical, bem como a era digital e seu potencial criminal diante do mau uso, quanto à segurança de informações pessoais e da intimidade, violando assim direitos fundamentais. (CHEVALLIER, 2009, p. 36-37).

As transformações nas relações múltiplas, oriundas das novas tecnologias e da globalização perante as relações de trabalho, as garantias de direito ao cidadão, os efeitos da economia sobre as relações público/privada, eclodiram numa crise democrática, e consequentemente um abalo no sistema de garantia de direitos fundamentais. Perante a atual situação, haveria como assegurar no futuro os direitos através de alguma outra forma de governo? Qual o papel do indivíduo na esfera pública?

\section{2 - Direitos fundamentais ameaçados em período de crise democrática.}

O cidadão é um membro ativo e participativo de uma comunidade política, mobilizado por uma virtude cívica que se revela a partir da autocompreensão ética compartilhada de uma comunidade.

Em face dessa concepção filosófica, para Habermas, o sistema de direitos não é cego em relação às diferenças culturais, procurando desenvolver uma perspectiva procedimental com fulcro na concepção de cooriginariedade entre autonomia pública e privada. Sem direitos fundamentais não haveria como estabelecer as condições procedimentais necessárias ao exercício da autonomia pública; mas, sem o exercício de sua autonomia pública, os cidadãos não são capazes de articular discursivamente suas concepções de bem. Portanto, quando o Poder Judiciário concretiza direitos fundamentais sociais contra a inércia das maiorias parlamentares, é possível afirmar que ele está resguardando condições procedimentais que viabilizam o funcionamento da democracia. (HABERMAS, 2002). 
Em contraposição a Habermas, surge em Honneth um modelo mais profundo de formação democrática da vontade política, no qual "o surgimento da liberdade individual da comunicação não é obtida do discurso intersubjetivo, mas da cooperação comunal." (HONNETH, 2001, p. 86). Segundo Bunchaft (2009, p. 157), acerca da perspectiva de Honneth, "os procedimentos democráticos só resultam na construção de uma sociedade mais justa, se esta consagra uma divisão do trabalho na qual cada indivíduo alcança efetiva estima social por suas habilidades e talentos", assumindo ocupações socialmente estimadas, pois "a esfera pública só funciona adequadamente se todos os indivíduos são incluídos no processo de reprodução do bem comum". (BUNCHAFT, 2009, p. 157).

Também é importante assinalar que a seleção das teorias utilizadas na sistematização dos modelos de esfera pública, bem como sua análise e interpretação, são orientadas por uma posição concreta frente à democracia e ao papel dos sistemas técnicos de comunicação na vida política, a saber: a crença de que as ideias e práticas democráticas só podem ser protegidas na medida em que elas se enraízam na vida política, social e econômica. (HELD, 2012, p. 22).

Já para Giovanni Sartori (1994, p. 162-163), o liberalismo pode ser considerado, muito simplesmente, como a teoria e a prática da defesa jurídica, através do Estado constitucional, da liberdade política individual. Em uma analogia à metáfora homérica da condição humana, pode-se dizer que o pensamento político liberal se debate entre o Silas da limitação do poder do Estado e a Caribdes da inserção do poder popular no Estado. As várias versões da democracia liberal refletem a virada do timão ao dispor de uma ou outra dessas forças.

O desafio da democracia para David Held refere-se, mais necessariamente, à introdução de procedimentos que primem pela formulação de preferências justificáveis, cuidadosamente examinadas, coerentes, situacionalmente abstratas e validadas socialmente. (HELD, 2012, p. 333-334).

Dentre as formas sugeridas pelos deliberacionistas para o aumento do elemento deliberativo nas democracias modernas, estão a introdução de pesquisas deliberativas, dias de deliberação e de júris de cidadãos, a ampliação dos mecanismos de informação dos eleitores e de comunicação, a reforma da educação cívica para melhorar a possibilidade de eleições maduras e o financiamento público de grupos cívicos e de associações que buscam o compromisso com a política deliberativa. (HELD, 2012, p. 351-357). 
Nas democracias de massas, o aprofundamento da democracia anda pari passu com a democratização das comunicações. E essa democratização ocorre conjuntamente, embora não ao mesmo tempo, em duas direções: (a) liberalização e/ou contestação pública, que pode ser traduzida pela condição de uma esfera pública ativa, e (b) ampliação dos espaços de participação política da sociedade civil. A participação é tomada como um ideal intermediário e não como um fim em si mesmo (Sartori, 1994).

Em suma, uma participação na deliberação pública, assim uma participação em termos de interesse, atenção, informação e competência e participação em termos de manifestação de apoio a ideias, propostas, reivindicações etc., uma participação em termos de compartilhamento de poder na formação das opiniões que legitimarão e desembocarão em ações administrativas e legais.

\section{CONSIDERACÕES FINAIS}

Ao finalizar o presente estudo acerca dos direitos fundamentais perante a crise democrática, tendo como preocupação a garantia do futuro destes direitos, é mister enfatizar que o objetivo principal foi investigar a formação do estado e as denominações de democracia frente a continuidade dos direitos fundamentais. Chega-se a um nível de aprofundamento satisfatório, haja vista as múltiplas variáveis que existem, devido à complexidade do Estado.

É relevante frisar que a pesquisa, mesmo sendo tão somente teórica, não considerou a existência de um sujeito abstrato, mas sim de um sujeito de carne e osso, que sente a dor da ausência de condições materiais para a vida digna. No entendimento de Peces Barba (1999, p. 182), a finalidade última dos direitos fundamentais é "garantir a igualdade mínima", que o cidadão tenha a universalização do acesso ao que mais se faz necessário para a dignidade humana.

Entretanto, apesar das garantias serem plausíveis, para a perfeita efetivação e continuidade no tempo, faltam esforços e atitudes políticas, bem como o gerenciamento de recursos para os investimentos em programas e projetos para a sua viabilidade.

Entretanto, há escassez de recursos públicos. Para Paul Singer (2003, p. 254), o problema reside na ascensão da doutrina neoliberal, a qual tem os direitos sociais como inimigo do sistema. Na medida em que o Estado é paternalista, novas exigências surgem da sociedade, transformando-o no "polvo de mil tentáculos", no dizer de Bobbio (2011, p. 144) 
em $O$ Futuro da democracia. Este Estado gigantesco acaba não conseguindo atender às demandas, ficando também sujeito à corrupção e desvios de dinheiro cada vez maiores, eclodindo em crise e na opressão de direitos.

Todavia, a democracia deliberativa é o caminho mais seguro na positivação e garantia dos direitos fundamentais. Ferrajoli (2011, p. 30) é enfático ao afirmar que ocorrendo a supressão da maioria dos métodos democráticos, não ocorre somente a extinção dos direitos à liberdade e dos direitos sociais, mas também dos "direitos políticos, do pluralismo, da separação dos poderes, da representação", ou seja, de todo o regramento que compõe o sistema político, e sendo assim, a democracia de fato não existe, mesmo que exista legalmente.

A democracia é um processo político repleto de contrassensos, tanto na sua forma quanto na sua dimensão e, principalmente, na sua execução perante a um Estado concreto, visando a superação das imensas desigualdades que pesam sobre a sociedade. (CADEMARTORI, 2011, p. 14).

Dentre as formas sugeridas pelos deliberacionistas para o aumento do elemento deliberativo nas democracias modernas, estão a introdução de pesquisas deliberativas, dias de deliberação e de júris de cidadãos, a ampliação dos mecanismos de informação dos eleitores e de comunicação, a reforma da educação cívica para melhorar a possibilidade de eleições maduras e o financiamento público de grupos cívicos e de associações que buscam o compromisso com a política deliberativa. (HELD, 2012, p. 351-357).

A hipótese de que mesmo o Estado tendo seus dirigentes envolvidos em crise, a cooperação democrática juntamente com mecanismos de informação e políticas públicas focadas, é possível atravessar períodos de crise garantindo os direitos fundamentais. Entretanto, não é sem prejuízos ao cidadão, pois a democracia deliberativa por si só, não possui todas as respostas e mecanismos para uma perfeita e eficiente gestão pública. Mas é o sistema de governo que melhor resposta oferece ao ser abalo por uma crise.

Com isso, foi possível compreender o efeito de uma crise democrática na efetividade dos direitos fundamentais, a qual provem de uma dinâmica forçada pela globalização e pelas novas tecnologias, que exigem um direito transnacional e ou novas soluções para as crises da atualidade. No decorrer do estudo a intencionalidade foi de demonstrar que o Estado possui condições de garantir a efetividade dos direitos fundamentais, mesmo em período de crise, mesmo que através de meios como o judiciário e uma gestão eficiente dos recursos públicos. 
Por fim, importa salientar que, embora seja obrigação do Estado garantir os direitos fundamentais, não se acolhe uma situação de dependência das pessoas ao Estado, ou que o Estado deve sustentar todos através de programas específicos. Entretanto é preciso se desvencilhar da ideia de que o Estado é um pai que deve tudo prover a seus filhos, pois o assistencialismo é inimigo da cooperação democrática. 


\section{REFERÊNCIAS}

BOBBIO Norberto, Quais as alternativas à democracia socialista? In: BOBBIO, Norberto. Qual socialismo?/debate sobre uma alternativa. Tradução de Iza de S. Freaza. Rio de Janeiro: Paz e Terra, 1983a.

BOBBIO Norberto. Liberalismo e democracia. Tradução Marco Aurélio Nogueira. 6. ed. São Paulo: Brasiliense, 2000. v. 1.

BOBBIO, Norberto. A era dos direitos. Rio de Janeiro: Campus, 1992.

BOBBIO, Norberto. Democracia. In: BOBBIO, Norberto; MATTEUCCI, Nicola; PASQUINO, Gianfranco. Dicionário de política. Trad. Carmen C, Varriale et al.; Coord. trad. João Ferreira; Rev. geral João Ferreira e Luis Guerreiro Pinto Cacais. 11. ed. Brasília: Editora Universidade de Brasília, 1998. v. 1, p. 319-329.

BOBBIO, Norberto. Estudios de historia de la filosofia/De Hobbes a Gramisci. Tradução de J. C. Bayon. Madrid: Debate, 1985.

BOBBIO, Norberto. O futuro da democracia: uma defesa das regras do jogo. Tradução Marco Aurélio Nogueira. 12. ed. Rio de Janeiro: Paz e Terra, 2011.

BONAVIDES, Paulo. Teoria constitucional da democracia participativa. São Paulo: Malheiros, 2001.

BRASIL. . Constituição da República Federativa do Brasil, 05 out. 1988. Diário da República Federativa do Brasil, 06 out. 1988. Disponível em: <

http://www.planalto.gov.br/ccivil 03/Constituição/Constituição.htm >. Acesso em: 20 Jul. 2017.

BUNCHAFT, Maria Eugenia. Entre Cooperação Reflexiva e Democracia Procedimental. Sequência, vol. 30, n. 59. Florianópolis: Fundação Boiteux, 2009.

CADERMATORI, Daniela Mesquita Leutchukde. O diálogo democrático. Curitiba: Juruá, 2011.

CANOTILHO, José Joaquim Gomes. (Org.). Comentários à Constituição do Brasil. São Paulo: Saraiva/Almedina, 2013.

CANOTILHO, José Joaquim Gomes. Direito constitucional e teoria da Constituição. 5. ed. Coimbra: Almedina, 2002.

CHEVALLIER, JACQUES. O Estado Pós-Moderno. Tradução de Marçal Justen Filho; Belo Horizonte: Fórum, 2009.

CORTE INTERAMERICANA DE DIREITOS HUMANOS.(CORTEIDH). [S.1.], Disponível em: 〈http://www.corteidh.or.cr/ > Acesso em: 15 jul. 17.

DANTAS, Paulo Roberto de Figueiredo. Curso de Direito Constitucional. São Paulo: Atlas, 2014.

DWORKIN, Ronald. Levando os direitos a sério. Tradução e notas Nelson Boeira. São Paulo:

Martins Fontes, 2002.

FERRAJOLI, Luigi. Democracia y garantismo. Madrid. Editora Trotta, 2010.

FERRAJOLI, Luigi. Democracia y garantismo. Tradução.Christian Courtis. Madrir: Trota, 2008.

FERRAJOLI, Luigi. Derechos y garantías. La ley del más débil. Traducción de Perfecto Andrés Ibánes y Andrea Greppi. 5 ed. Madrid: EditoraTrotta, 2004.

FERRAJOLI, Luigi. Poderes salvajes: la crisis de la democracia constitucional. Tradução: Perfecto Andrés Ibáñez. Madrid: Minima Trotta. 2011. 
FERREIRA, Aurelio Buarque de Holanda. Novo dicionário Aurélio da língua portuguesa. 2ª ed. Rio de Janeiro: Nova fronteira, 1995.

HABERMAS, Jürgen A crise de legitimação no capitalismo tardio. Rio de Janeiro. Tempo Brasileiro, 2002.

HABERMAS, Jürgen. Transformação estrutural da esfera pública: investigações quanto a uma categoria da sociedade burguesa. Rio de janeiro: Tempo Brasileiro, 2003.

HELD, David. Modelos de democracia. 3. ed. Madrid: Alianza Editorial, 2012.

HONNETH, Axel. "Democracia como Cooperação Reflexiva. John Dewey e a Teoria Democrática hoje". In: SOUZA, Jessé (org.). Democracia hoje - Novos desafios para a teoria democrática contemporânea. Brasília: UNB, 2001.

LENZA, Pedro. Direito constitucional: esquematizado. 16. ed. rev., atual. e ampl. São Paulo: Saraiva, 2013.

MATTEUCCI, Nicola. Verbete liberalismo. In: BOBBIO, Norberto et al: Dicionário de política. Tradução de J. M. Cascais et al:. Brasília: UnB, 1983.

MORAIS, Alexandre de. Direito Constitucional. 25 ed. São Paulo: Atlas, 2010.

MORAIS, José Luis Bolzan de. As crises do Estado e da Constituição e a transformação espacial (espaço-temporal) dos direitos humanos. 2ª ed. Porto Alegre, Livraria do Advogado, 2011.

NEVES, Marcelo. Transconstitucionalismo. São Paulo: Editora VWF Martins Fontes, 2009.

ORGANIZAÇÃO DAS NAÇÕES UNIDAS (ONU). Declaração Universal dos Direitos Humanos. . [S.l.], 1789. Disponível em; < http://www.onu.org.br/conheca-a-onu/documentos >.Acesso em: 05 ago. 2017.

ORGANIZAÇÃO MUNDIAL DO COMÉRCIO. (OMC). 2013. Disponível em: < http://www.wto.org/spanish/thewto_s/whatis_s/tif_s/org6_s.htm > Acesso em: 16 jul. 17.

PECES-BARBA MARTÍNEZ, Gregorio. Curso de derechos fundamentales. Teoria general. Madrid: Universidade Carlos III de Madrid. 1995.

PECES-BARBA MARTÍNEZ, Gregorio. Los derechos econômicos, sociales y culturales: su génesis y su concepto. Derechos y Liberdad. - Revista del Instituto Bartolomé de las Casas, 1999.

PÉREZ LUÑO, Antonio Enrique: Los derechos fundamentales. Madrid: Editorial Tecnos, 2005.

SARLET, Ingo Wolfgang. A eficácia dos direitos fundamentais: uma teoria geral dos direitos fundamentais na perspectiva constitucional. 11. Ed. rev. atual. Porto Alegre: Livraria do Advogado Editora, 2012.

SARTORI, Giovanni. Teoria da democracia revisitada, 1. O debate contemporâneo. São Paulo: Ática, 1994.

SILVA, José Afonso da. Curso de Direito Constitucional. Positivo. 22 ed. São Paulo: Malheiros, 2003.

SINGER, Paul. A cidadania para todos. In: PINSKY, Jaime; Carla Bassanezi (Orgs.). História da cidadania. São Paulo: Contexto, 2003.

SORENSEN, GEORG. La transformación del Estado Más allá del mito del Repliegue:

Traducción: RAMÓN COTARELO. Tirant Lo Blanch Valencia, 2010. p. 41.

SOUZA NETO, Cláudio Pereira de. Teoria constitucional e Democracia Deliberativa. Um estudo sobre o papel do direito na garantia das condições para a cooperação na deliberação democrática. Rio de Janeiro: Renovar, 2006. 
STRECK, Lenio Luiz. Jurisdição constitucional e decisão jurídica. 3. ed. São Paulo: Revista dos Tribunais, 2013.

TORRES, Ricardo Lobo. O direito ao mínimo existencial. Rio de Janeiro: Renovar, 2009. 